\title{
Analisis Vitamin B6 (Piridoksin) pada Sediaan Tablet Multivitamin Neurotropik Menggunakan Spektrofotometri UV-Vis
}

\author{
Vevi Maritha* \\ Sekolah Tinggi Ilmu Kesehatan Bhakti Hudasa Mulia Madiun, Jawa Timur, Indonesia
}

Analisis vitamin B6 dalam sediaan tablet multivitamin neurotropik membutuhkan metode yang sederhana, cepat serta murah. Salah satu metode yang memiliki kriteria tersebut adalah spektrofotometri UV-Vis. Analisis vitamin B6 menggunakan spektrofotometri UV Vis berlangsung cepat sehingga mampu menghambat degradasi senyawa sehingga hasil analisis yang diperoleh lebih akurat. Pemilihan panjang gelombang maksimal tunggal untuk vitamin B6 akan mampu memisahkan dengan komponen vitamin B1 dan B6 meskipun ketiganya sama-sama larut dalam air. Kondisi optimal analisis vitamin B6 pada sampel vitamin neurotropik dengan metode spektrofotometri UV-Vis adalah pada panjang gelombang $325 \mathrm{~nm}$ dengan menggunakan pelarut air. Hasil kurva kalibrasi pada seri kadar 60 ppm, 70 ppm, 80 ppm, 90 ppm, 100 ppm, 110 ppm, 120 ppm dan 130 ppm memiliki nilai $r$ 0, 9965. Penetapan kadar vitamin B6 menggunakan sampel 3 merk sediaan multivitamin neurotropik. Kadar teoritis yang diukur adalah $100 \mathrm{ppm}$, sedangkan perolehan kembali pada sampel multivitamin neurotropik merk A masing-masing adalah 98,24 ppm, 95 ppm dan 95,78 ppm dengan niali standar deviasi (SD) sebesar 1,69. Kadar teoritis vitamin B6 pada sampel multivitamin neurotropik merk B adalah 100 ppm, sedangkan perolehan kembali masing-masing adalah 99 ppm, 102 ppm dan 98 ppm dengan SD sebesar 1,15. Penetapan kadar vitamin B6 pada multivitamin neurotropik merk C kadar teoritis yang diukur adalah 100 ppm, sedangkan perolehan kembali masing-masing adalah 102 ppm, 101 ppm dan 99 ppm dengan nilai SD sebesar 1,53. Perolehan kembali penetapan kadar vitamin B6 telah sesuai dengan persyaratan AOAC, yaitu untuk kadar analit 100 ppm \% recoverinya 90-107\%. Nilai SD dari ketiga sampel multivitamin neurotropik yang kurang dari 2 menunjukkan bahwa hasil penetapan kadar vitamin B6 dapat diterima. Hasil penelitian ini menunjukkan bahwa vitamin B6 dalam sampel multivitamin neurotropik dapat dianalisis menggunakan spektrofotometri UV-VIS pada panjang gelombang $325 \mathrm{~nm}$ menggunakan pelarut air.

Kata kunci: Vitamin B6, Spektrofotometri UV-Vis, multivitamin, neurotropik

\section{Vitamin B6 (Pyridoxine) Analysis on Neurotropics Multivitamin Tablet Using Spectrophotometry UV-Vis}

Vitamin B6 analysis in neurotrophic multivitamin tablet preparations requires a simple, fast and cheap method. UV-Vis spectrophotometer is having these criteria. Vitamin B6 analysis using UV Vis spectrophotometry is very quick so that the substance degradation can be inhibited and the results obtained will be accurate. Selection of single maximum wavelength for vitamin B6 will be able to separate with other components of vitamins B1 and B6 although all three are soluble in water. The optimal condition of vitamin B6 analysis in neurotropic multivitamin samples was using UV-Vis spectrophotometry at $325 \mathrm{~nm}$ wavelength. The solvent used is water. The calibration result curve in series of 60 ppm, 70 ppm, 80 ppm, 90 ppm, 100 ppm, 110 ppm, 120 ppm and 130 ppm have $r$ value of 0,9965.Determination of vitamin B6 levels using three brands of neurotrophic multivitamin samples performed. The measured theoretical level was $100 \mathrm{ppm}$, whereas the recovery of neurotropic multivitamin $A$ samples were $98.24 \mathrm{ppm}, 95 \mathrm{ppm}$ and $95.78 \mathrm{ppm}$ respectively with SD 1.69. The theoretical content of vitamin B6 in the neurotrophic multivitamin sample of B brand was $100 \mathrm{ppm}$, whereas the recovery was $99 \mathrm{ppm}, 102$ ppm and 98 ppm with SD 1.15. Determination of vitamin B6 concentration in the neurotropic multivitamin brand $\mathrm{C}$ the measured theoretical level was 100 ppm, while the recovery was 102 ppm, 101 ppm and 99 ppm with SD value of 1.53. The recovery of vitamin B6 level determination has been in accordance with AOAC requirements, ie for $100 \%$ ppm $\%$ analytical calculation $90-107 \%$. The primary SD values of the three neurotrophic multivitamin samples of less than 2 indicate that vitamin B6 levels are acceptable. The results of this study indicate that vitamin B6 in a neurotrophic multivitamin sample can be analyzed using UV-VIS spectrophotometry at a wavelength of $325 \mathrm{~nm}$ using a water solvent.

Keywords : Vitamin B6, Spectrophotometri UV-Vis, multivitamin, neurotropic.

${ }^{*}$ Corresponding author: Sekolah Tinggi IImu Kesehatan Bhakti Husada Mulia Madiun, Jalan Taman Praja No.25 Surabaya, e-mail: vv.maritha@gmail.com 


\section{PENDAHULUAN}

Vitamin B6 (piridoksin) diperlukan dalam beberapa proses metabolisme. Tubuh membutuhkan vitamin B6 untuk reaksi lebih dari 100 enzim, perkembangan otak selama masa kehamilan, serta fungsi kekebalan tubuh. Vitamin B6 juga berperan sebagai kofaktor dalam reaksi enzimatis tubuh yang essensial. Pada orang dewasa kebutuhan vitamin B6 adalah $100 \mathrm{mg}$ per hari, sedangkan pada anak usia 1 sampai 3 tahun $30 \mathrm{mg}$, anak usia 4 sampai 8 tahun $40 \mathrm{mg}$, anak usia 9 sampai 13 tahun $60 \mathrm{mg}$ dan pada remaja 14 tahun sampai 18 tahun 80 mg per hari. Kekurangan vitamin B6 dapat menyebabkan anemia, ruam kulit, depresi serta system kekebalan tubuh yang lemah. Vitamin B6 sering dikombinasikan dengan vitamin B1 dan B12 sebagai vitamin neurotropi. Kombinasi dengan vitamin B1 dan B12 akan memperbaiki serta mengoptimalkan sistem syaraf. Hal ini menunjukkan pentingnya asupan vitamin B6 yang cukup pada tubuh (Mooney et al, 2009; $\mathrm{NIH}, 2016)$.

Analisis vitamin B6 dalam beberapa sampel banyak yang sudah dipublikasikan. Analisis vitamin B6 diantaranya menggunakan HPLC (High Performance Liquid Chromatography), GC (Gass Chromatography) serta menggunakan FITR. Penggunaan HPLC dalam analisis memiliki beberapa keterbatasan diantaranya optimasi yang memakan waktu cukup lama, pemilihan fase gerak yang cukup rumit serta instrument yang cukup mahal, begitu juga analisis vitamin B6 menggunakan GC maupun FTIR. Kedua instrument ini juga memiliki beberapa kekurangan ketika akan digunakan untuk analisis vitamin B6. GC dan FTIR merupakan metode analisis yang rumit dan membutuhkan preparasi sampel yang lama, sehingga dibutuhkan metode analisis yang simple, cepat serta dengan biaya yang relative murah (Amaro et al., 2014, Vergara et al., 2005; Nugrahani et al., 2016).

Analisis vitamin B6 dalam sediaan tablet multivitamin neurotropik membutuhkan metode yang simple, cepat serta murah. Salah satu metode yang memiliki kriteria tersebut adalah spektrofotometer UV-Vis. Rentang panjang gelombang yang lebar akan mampu mendapatkan panjang gelombang maksimal untuk analisis vitamin B6. Analisis vitamin B6 menggunakan spektrofotometri UV Vis akan berlangsung cepat sehingga mampu menghambat degradasi sehingga hasil analisis yang diperoleh akurat. Pemilihan panjang gelombang maksimal tunggal untuk vitamin B6 akan mampu memisahkan dengan komponen lain yaitu vitamin B1 dan B6 meskipun ketiganya sama-sama larut dalam air. Hal ini juga menunjukkan bahwa analisis vitamin B6 menggunakan spektrofometri UV Vis juga selektif (Ham et al., 2012).

\section{Alat}

Alat yang digunakan dalam penelitian ini adalah spektrofotometri UV-Vis, sentrifuse, stirer, labu ukur 10,0 ml, labu ukur 100,0 ml, gelas beaker 100,0 ml, spatula, pipet ukur, kertas whattman dan pipet volume.

\section{Bahan}

Bahan yang digunakan dalam penelitian ini adalah standar vitamin B6 (piridoksin), aquades serta sampel vitamin neurotropik merk A, vitamin neurotropik merk B dan vitamin neurotropik merk $\mathrm{C}$.

\section{Tahapan Penelitian}

Pembuatan baku induk 1000 ppm

Ditimbang 10,0 mg baku vitamin B6 kemudian dilarutkan menggunakan aquades 10,0 ml. Larutan ini distirer kemudian disaring menggunakan kertas whattman. Membuat baku vitamin B6 100 ppm, dengan cara dipipet 1,0 ml dari baku induk dilarutkan dalam 10,0 ml aquades, kemudian digunakan untuk menetapkan panjang gelombang maksimal.

\section{Pembuatan Kurva Baku Vitamin B6}

Dibuat larutan $60 \mathrm{ppm}, 70 \mathrm{ppm}, 80 \mathrm{ppm}$, $90 \mathrm{ppm}, 100 \mathrm{ppm}, 110 \mathrm{ppm}, 120 \mathrm{ppm}$ dan 130 ppm dari baku induk $1000 \mathrm{ppm}$. Kemudian dilihat nilai absorbansinya. Kurva baku dibuat antara seri kadar dengan nilai absorbansi melalui regresi linier.

\section{Penetapan Kadar Vitamin B6 Dalam Sampel}

Penetapan kadar vitamin B6 dalam sampel vitamin neurotropik merk A, B dan C. ditimbang 20 tablet kemudian dihitung bobot rata-ratanya, kemudian dihaluskan. Timbang sampel yang sudah menjadi serbuk sesuai bobot rata-rata tablet. Masukkan dalam labu ukur 100,0 ml tambah aquades sampai batas. Stirer larutan tersebut kemudian sentrifuse. Hasil sentrifuse disaring menggunakan kertas whattman. Ambil 1,0 ml larutan masukkan dalam labu ukur 10,0 ml, ditambah aquades sampai batas. Kemudian dianalisis menggunakan spektrofotometri UV-Vis pada panjang gelombang maksimal. Catat nilai absorbansinya untuk dihitung kadarnya menggunakan persamaan regresi linier yang diperoleh dari kurva baku.

\section{HASIL DAN PEMBAHASAN}

Hasil penetapan panjang gelombang maksimal adalah $325 \mathrm{~nm}$ dengan nilai absorbansi o,558 dan kurva baku vitamin B6 dapat dilihat pada gambar 1 dan 2.

Hasil perhitungan kadar dalam sampel sediaan tablet neurotropik dapat dilihat pada tabel 1. Penggunaan spektrofotometer UV-Vis untuk analisis vitamin dan obat telah banyak digunakan, termasuk pada vitamin B6 atau piridoksin. Analisis vitamin B6 menggunakan 
spektrofotometri UV-Vis adalah suatu metode analisis yang simple. Kelebihan lain dari metode analisis ini adalah cepat, tidak memerlukan biaya yang besar dan mudah dilakukan. Jumlah sampel dan pelarut yang dibutuhkan juga sedikit, namun tetap memberikan hasil yang akurat. Analisis yang cepat akan memberikan efisisensi waktu dalam mengerjakannya. Kemungkinan terjadinya kerusakan vitamin B6 yang dilarutkan pada pelarutnya sebelum dianalisis juga dapat dicegah.

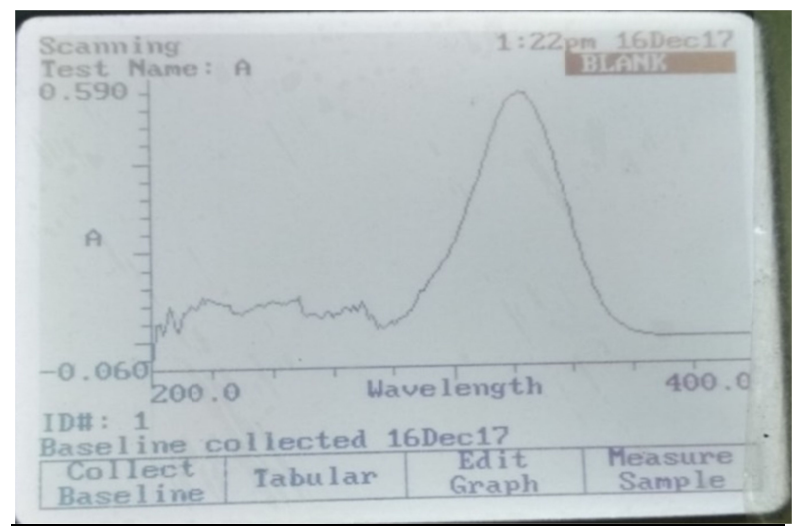

Gambar 1. Panjang gelombang maksimum Vitamin B6.

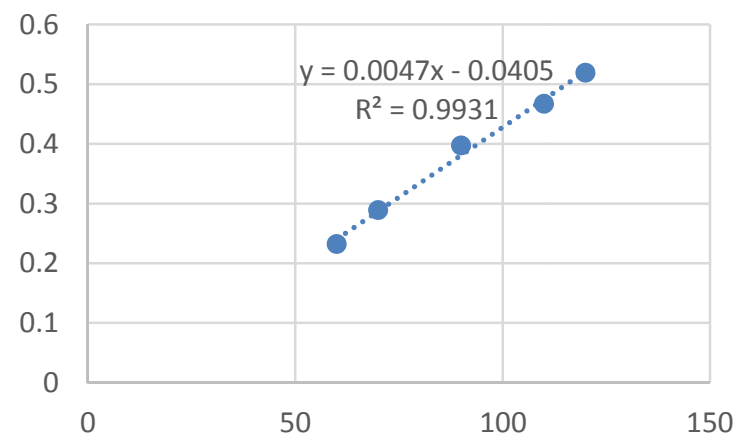

Gambar 2. Kurva Linieritas Vitamin B6.

Penentuan panjang gelombang maksimal dilakukan dengan menggunakan standar baku vitamin B6 pada kadar 100 ppm. Pada analisis vitamin B6 menggunakan pelarut air karena piridoksin termasuk vitamin larut air. Pemilihan air sebagai pelarut karena ketersediannya yang melimpah dan mudah didapatkan. Penentuan panjang gelombang maksimal dilakukan dengan melakukan scaning pada panjang gelombang 200-400 nm. Vitamin B6 memberikan serapan pada daerah UV sehingga untuk analisis menggunakan spektrofotometri serapan dibaca pada panjang gelombang antara $200 \mathrm{~nm}$ sampai dengan $400 \mathrm{~nm}$. Panjang gelombang maksimal untuk analisis vitamin B6 adalah $325 \mathrm{~nm}$ yang memberikan serapan 0,558 A. Nilai serapan optimum analisis menggunakan spektrofotometri adalah o,2 sampai o,8 A, sehingga nilai serapan saat penentuan panjang gelombang maksimal telah sesuai. Hasil penetapan panjang gelombang maksimal terlihat pada Gambar 1. Panjang gelombang maksimal penetapan kadar vitamin B6 yang telah dipubikasikan adalah $290 \mathrm{~nm}$. Perbedaan ini dimungkinkan karena adanya perbedaan instrument yang digunakan serta perbedaan kondisi laboratorium. Setelah penentuan panjang gelombang maksimal tahapan selanjutnya adalah membuat kurva baku vitamin B6.

Kurva baku vitamin B6 dibuat dengan 5 titik yaitu pada kadar 60 ppm, 70 ppm, 90 ppm, $110 \mathrm{ppm}$ dan $120 \mathrm{ppm}$. Nilai absorbansi pada masing masing kadar tersebut adalah o,232A, 0,289A, 0,397A, 0,467A dan 0,519A. Nilai koefisien korelasi (r) sebesar 0,9965. Terlihat bahwa analit memberikan respon yang cukup linier terhadap kadar. Hasil uji linieritas dapat dilihat pada Tabel 1 dan Gambar 2. Setelah uji linieritas selanjutnya metode ini diaplikasikan pada sampel yang mengandung vitamin B6 pada sediaan vitamin neurotropik.

Penetapan kadar vitamin B6 menggunakan sampel sediaan multivitamin neurotropik yang dilakukan pada 3 merk. Hasil penetapan kadar vitamin B6 pada sampel terlihat pada Tabel 1 . Sampel yang digunakan adalah multivitamin neurotropik merk A, merk B dan merk C. Pemilihan ketiga merk ini didasarkan atas penggunaannnya yang besar di masyarakat atas dasar penjualannya di apotek. Penetapan kadar vitamin B6 pada multivitamin neurotropik merk A dilakukan replikasi 3 kali. Kadar teoritis yang diukur adalah 100 ppm, sedangkan perolehan kembali masing-masing adalah 98,24 ppm, 95 ppm dan 95,78 ppm. Dari ketiga nilai ini diketahui bahwa niali standar deviasi (SD) sebesar 1,69. Hal ini menunjukkan bahwa hasil penetapan kadar vitamin B6 dalam sampel multivitamin neurotropik merk A dapat diterima. Penetapan kadar vitamin B6 pada multivitamin neurotropik merk B juga dilakukan replikasi 3 kali. Kadar teoritis yang diukur adalah 100 ppm, sedangkan perolehan kembali masing-masing adalah 99 ppm, 102 ppm dan 98 ppm. Dari ketiga nilai ini diketahui bahwa nilai standar deviasi (SD) sebesar 1,15. Hal ini menunjukkan bahwa hasil penetapan kadar vitamin B6 dalam sampel multivitamin neurotropik merk $\mathrm{B}$ juga dapat diterima. Penetapan kadar vitamin B6 pada multivitamin neurotropik merk $\mathrm{C}$ dilakukan replikasi 3 kali. Kadar teoritis yang diukur adalah 100 ppm, sedangkan perolehan kembali masingmasing adalah 102 ppm, 101 ppm dan 99 ppm. Dari ketiga nilai ini diketahui bahwa nilai standar deviasi (SD) sebesar 1,53. Perolehan kembali penetapan kadar vitamin B6 telah sesuai dengan persyaratan AOAC, yaitu untuk kadar analit 100 ppm \% recoverinya 90-107\%. Nilai SD dari ketiga sampel multivitamin neurotropik yang kurang dari 2 menunjukkan bahwa hasil penetapan kadar vitamin B6 dapat diterima. Hasil penelitian ini menunjukkan bahwa vitamin B6 dalam sampel multivitamin neurotropik dapat dianalisis menggunakan spektrofotometri UV-VIS pada panjang gelombang $325 \mathrm{~nm}$ menggunakan 
pelarut air (Nanjing University, 2002; AOAC, 1998).

\section{KESIMPULAN}

Vitamin B6 (piridoksin) dalam sampel vitamin neurotropik dapat dianalisis menggunakan Spektrofotometri UV-VIS pada panjang gelombang $325 \mathrm{~nm}$ menggunakan pelarut air. Analisis vitamin B6 menggunakan Spektrofotometri UV-VIS merupakan metode analisis yang simple, mudah, efisien biaya serta memerlukan sampel dan pelarut dalam jumlah sedikit.

TABEL 1. Hasil Perhitungan Kadar dalam Sampel Tablet

Neurotropik.

\begin{tabular}{cccccc}
\hline Sampel & Replikasi & $\begin{array}{c}\text { Kadar } \\
\text { (ppm) }\end{array}$ & $\begin{array}{c}\text { Perolehan } \\
\text { (ppm) }\end{array}$ & $\begin{array}{c}\text { \% } \\
\text { Recovery }\end{array}$ & SD \\
\hline A & 1 & 100 & 98,24 & 100 & \\
& 2 & 100 & 95 & 95 & 1,69 \\
& 3 & 100 & 95,78 & 96 & \\
B & 1 & 100 & 99 & 99 & \\
& 2 & 100 & 102 & 102 & 1,15 \\
& 3 & 100 & 98 & 98 & \\
C & 1 & 100 & 102 & 102 & \\
& 2 & 100 & 101 & 101 & 1.53 \\
& 3 & 100 & 99 & 99 & \\
\hline
\end{tabular}

\section{DAFTAR PUSTAKA}

Amaro, C., Flores, C., Diaz, M and Lidon F. 2014. Pyridoxine Analysis by High Performance Liquid Chromatography and Validation in Fortified Milk Powder. Acta Alimentaria. Vol 43 (2). p. 105-113

AOAC. 1998. AOAC Peer-Verified Methods Program, Manual on Policies and Procedures. Arlington, Amerika Serikat:AOAC

Ham, M., Albersen, M., Koning, T., Visser, G., Middendrop, A., Bosma, M., Duif, N and Valden M. 2012. Quantification of Vitamin B6 Vitamers in Human Cerebrospinal Fuid by Ultra Performance Liquid Chromatography-Tandem Mass Spectrometry. Analitica Chimica Acta. Vol 712. p. 108-114

Mooney, S., Leuendorf, J., Hendrickson, C and Hellmann, H. 2009. Vitamin B6 : A Long Known Compound of Surprising Complexity. Molecules Journal. Vol 14. p. 329-351.

Nanjing University. 2002. Simultaneous Determination of
Nicotinamid, Pyridoxine Hydrocloride, Thiamine Mononitrat, and Riboflavin in Multivitamin with Mineral Tablets by Reversed-phase Ion Pair High Performance Liquid Chromatography. Biomedical Chromatography. Vol 16. Pp 504-507.

National Institutes of Health. 2016. Vitamin B6 Fact Sheet for Consumers. National Institutes of Health. p.1-3

Nugrahanani, I and Kartini, C. 2016. Determination of Thiamine $\mathrm{HCl}$ (Vitamin B1) and Pyridoxine $\mathrm{HCl}$ (Vitamin B6) Content in Tablet by FTIR. International Journal of Pharmacy and Pharmaceutical Science. Vol 8. p. 257-264

Vergara, L., Squella, J., Strum, J., Baez, J and Camargo, C. 2005. Simultaneous Determination of Melatonin and Pyridoxine in Tablets by Gas Chromatography-Mass Spectrometry. Faculty of Chemical and Pharmaceutical Sciences University of Chile P.O. Box 233, Santiago, Chile. 